\title{
The 'one-pot' preparation of substituted benzofurans
}

\author{
Márton Csékei, ${ }^{a}$ Zoltán Novák, ${ }^{a}$ Géza Timári, ${ }^{b}$ and András Kotschy** \\ ${ }^{a}$ Department of General and Inorganic Chemistry, Eötvös Loránd University, Pázmány Péter s. \\ 1/A, H-1117 Budapest, Hungary, and \\ ${ }^{b}$ Chinoin Rt, Tó u. 1-5, H-1045 Budapest, Hungary \\ E-mail: kotschy@para.chem.elte.hu
}

\section{Dedicated to Professor Sándor Antus on the occasion of his $60^{\text {th }}$ birthday}

(received 31 Dec 03; accepted 19 May 04; published in the web 22 May 04)

\begin{abstract}
A simple one-pot procedure has been elaborated for the preparation of substituted benzofurans starting from halogenated phenols, and this method has been applied successfully to the total synthesis of dehydrotremetone, a natural product of White Snakeroot.
\end{abstract}

Keywords: Benzofurans, Sonogashira coupling, natural product, synthesis

\section{Introduction}

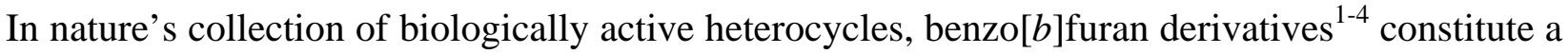
major group. They are usually important constituents of plant extracts used in traditional medicine, ${ }^{2}$ and some of them also play an important role in the natural defence mechanisms of their plants. These compounds include hydroxylated benzofurans such as Euparin ${ }^{5}$ (1, Figure 1.), Coumestrol $^{6}(2)$, dehydrotremetone ${ }^{7}$ (3), or Cicerfuran ${ }^{8}(4)$. Due to this effect, a synthetic route leading to hydroxylated benzofurans would be of general interest.<smiles>C=C(C)c1cc2cc(C(C)=O)c(O)cc2o1</smiles>

1<smiles>O=c1oc2cc(O)ccc2c2oc3cc(O)ccc3c12</smiles>

2<smiles>C=C(C)c1cc2cc(C(C)=O)ccc2o1</smiles>

3<smiles>COc1cc2c(cc1-c1cc3ccc(O)cc3o1)OCO2</smiles>

Figure 1 
An obvious approach would utilize the cross-coupling of the benzofuran and C2-substituent moieties as demonstrated for analogous systems by Timári. ${ }^{9}$ Unfortunately, extension of this procedure would require the selective preparation of differently substituted benzofurans, a task that has not been solved generally yet.

An alternate approach would achieve the formation of the benzofuran moiety through the ring closure of an $o$-alkynylphenol, ${ }^{10-15}$ available through the coupling of an aryl halide and the appropriate aryl acetylene.

In spite of the large number of publications describing the conversion of 2-halophenols to benzo[b]furans, ${ }^{10-15}$ the preparation of hydroxylated benzofurans has received only limited attention so far. ${ }^{12,14,15}$ By analogy, such a process would start from a halogenated dihydroxybenzene. These compounds usually fail to undergo Sonogashira coupling ${ }^{17}$ and the successful procedures on similar systems usually utilize the selective protection of the different hydroxyl groups or an equimolar amount of preformed organocopper reagent. ${ }^{15} \mathrm{~A}$ recent publication described the use of acetyl protecting groups that allowed for the efficient, 'one-pot' conversion of bromorezorcine (5, Figure 2.) to Cicerfuran (4). ${ }^{16}$

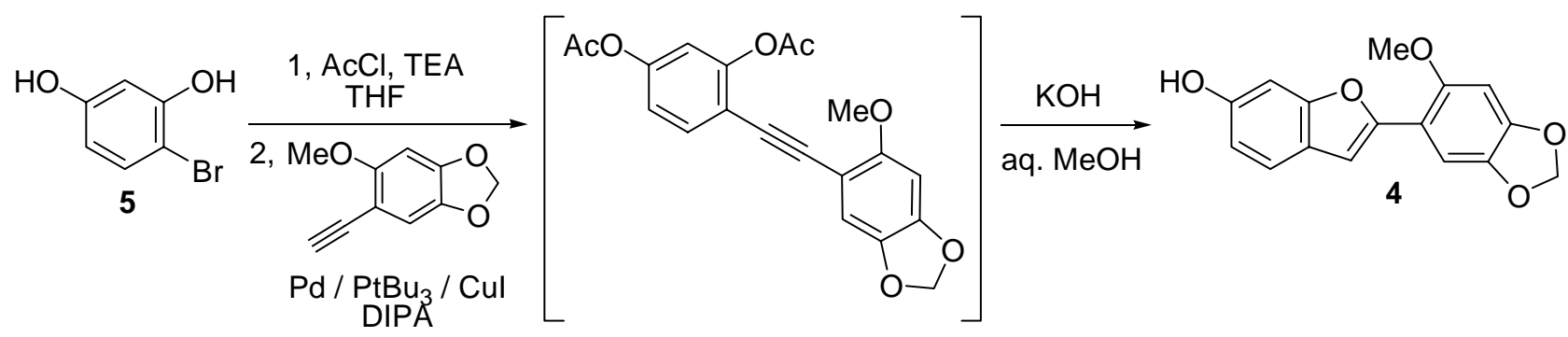

\section{Figure 2}

The present paper describes our efforts to extend the above mentioned strategy to the preparation of other hydroxylated benzofuran derivatives and to realize the 'one-pot' synthesis of dehydrotremetone (3).

\section{Results and Discussion}

The first set of experiments was directed towards the one-pot protection-coupling-cyclization of bromohydroquinone (6, Figure 3). Using the conditions established for Cicerfurane ${ }^{16}, 6$ was acetylated with 2 equivalents of acetyl chloride in absolute THF in the presence of triethylamine. The reaction was complete in a couple of minutes, as judged by TLC, and, subsequently, an excess of diisopropylamine, $2 \mathrm{~mol}$ equivalents of phenylacetylene, $5 \mathrm{~mol} \%$ palladium acetate, 7.5 mol\% tris(tert-butylphosphine) and 5 mol\% copper(I) iodide were added. ${ }^{17,18}$ The reaction vessel was sealed under argon and placed in a $60{ }^{\circ} \mathrm{C}$ oil bath. The Sonogashira coupling reached full conversion in 2 hours and the major product was identified by GC-MS as the expected 
intermediate shown in Figure 3. The vessel was opened and after the addition of aqueous methanol containing 10 equivalents of potassium hydroxide, the mixture was heated to $75{ }^{\circ} \mathrm{C}$ for 2 hours to achieve the removal of the protecting groups and initiate spontaneous ring closure. Following a standard workup procedure and chromatographic purification, the expected product, 2-phenyl-5-hydroxybenzofurane (7) was isolated in 52\% yield.
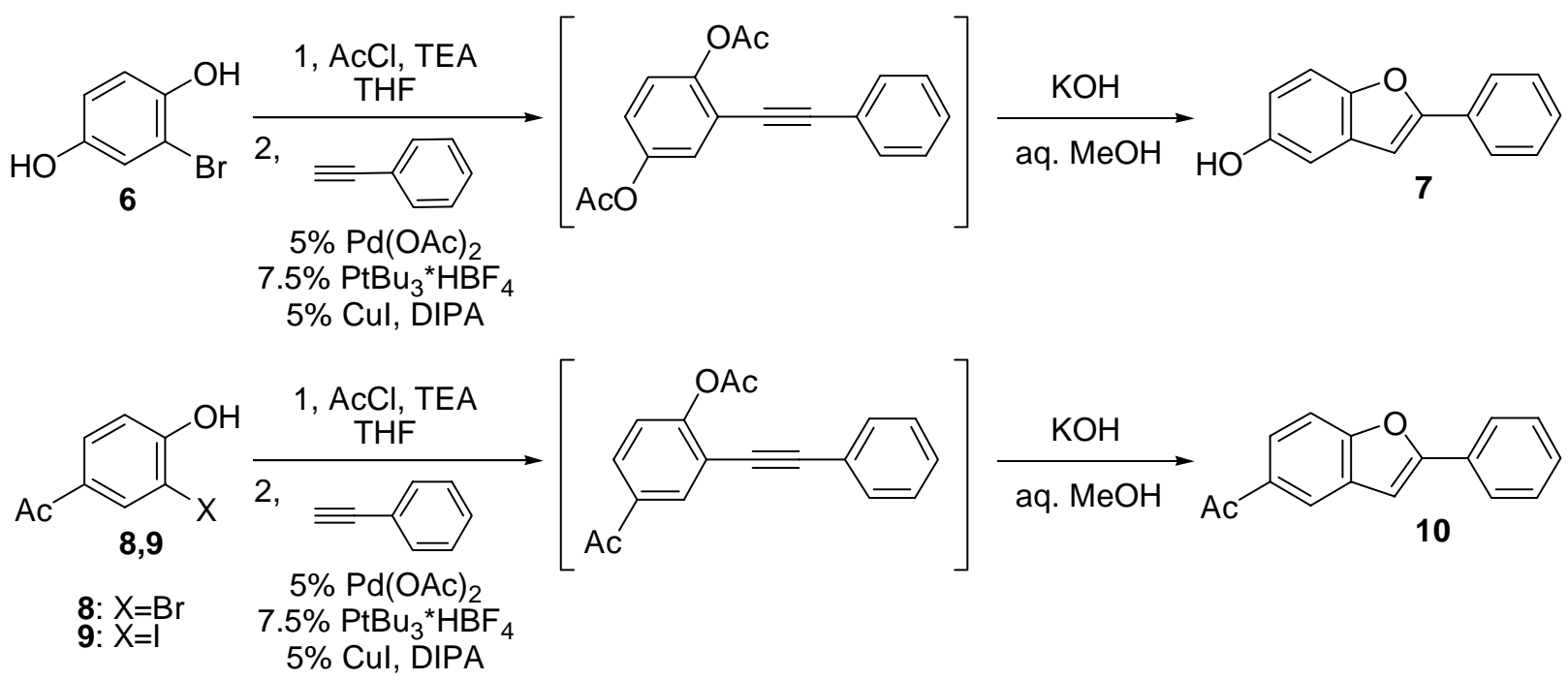

\section{Figure 3}

The preparation of 5-acetyl derivatives, another common structural motif in biologically active benzofurans, would utilize 3-halo-4-hydroxyacetophenones as starting materials. 3-Bromo4-hydroxyacetophenone (8) and 4-hydroxy-3-iodoacetophenone (9) were prepared by the FriedelCrafts acetylation of 2-bromophenol ${ }^{19}$ and the iodination of 4-hydroxyacetophenone. ${ }^{19}$ Attempts to prepare $\mathbf{8}$ according to a recent literature procedure ${ }^{20}$ were in vain, as the only product isolated was 3,5-dibromo-4-hydroxyacetophenone.

The one-pot transformations of 3-bromo-4-hydroxyacetophenone (8) and 4-hydroxy-3iodoacetophenone (9) into 5-acetyl-2-phenlybenzofuran (10) were equally successful. Acetylation was complete in a couple of minutes at room temperature and, after the addition of phenylacetylene, diisopropylamine and the catalyst system, the Sonogashira coupling reached full conversion in less than two hours in both cases. After the removal of the protecting group and spontaneous ring closure, 10 was isolated in good yield (74\% starting from 8 and 57\% starting from 9).

Another test of the efficiency of the developed procedure was our attempt to use 2-methyl-1buten-3-yne as the acetylene derivative. In this case the formed benzofuran would bear a 2propenyl substituent in position 2, just as in natural products Euparin (1) and dehydrotremetone (3). The use of this alkyne is somewhat challenging as its low boiling point $\left(32{ }^{\circ} \mathrm{C}\right)$ does not allow for use of the elevated temperatures usually required for the Sonogashira coupling, at least when using conventional glassware. Published procedures circumvent this inconvenience by 
converting the alkyne into a metal salt, e.g. copper(I) acetylide, ${ }^{15}$ requiring the use of an equimolar amount of a metal salt, a process that we tried to avoid, to reduce waste.

In the first set of experiments, bromohydroquinone (6) and 3-bromo-4-hydroxyacetophenone (8) (Figure 4.) were subjected to the one-pot benzofuran synthesis procedure. Following their acetylation, we were unable to achieve any conversion in the Sonogashira coupling with 2methyl-1-buten-3-yne keeping the reaction mixtures for a prolonged time (120 hours) in a $40{ }^{\circ} \mathrm{C}$ oil bath. The failure of these compounds to undergo the coupling was attributed to the decreased reactivity of the bromoarenes and was highly discouraging as the catalyst system used is considered to be one of the most active known for such couplings. ${ }^{18}$ Our best chance to initiate the Sonogashira coupling at ambient temperature in the one-pot procedure was the use of an iodoarene instead of the bromo derivative.
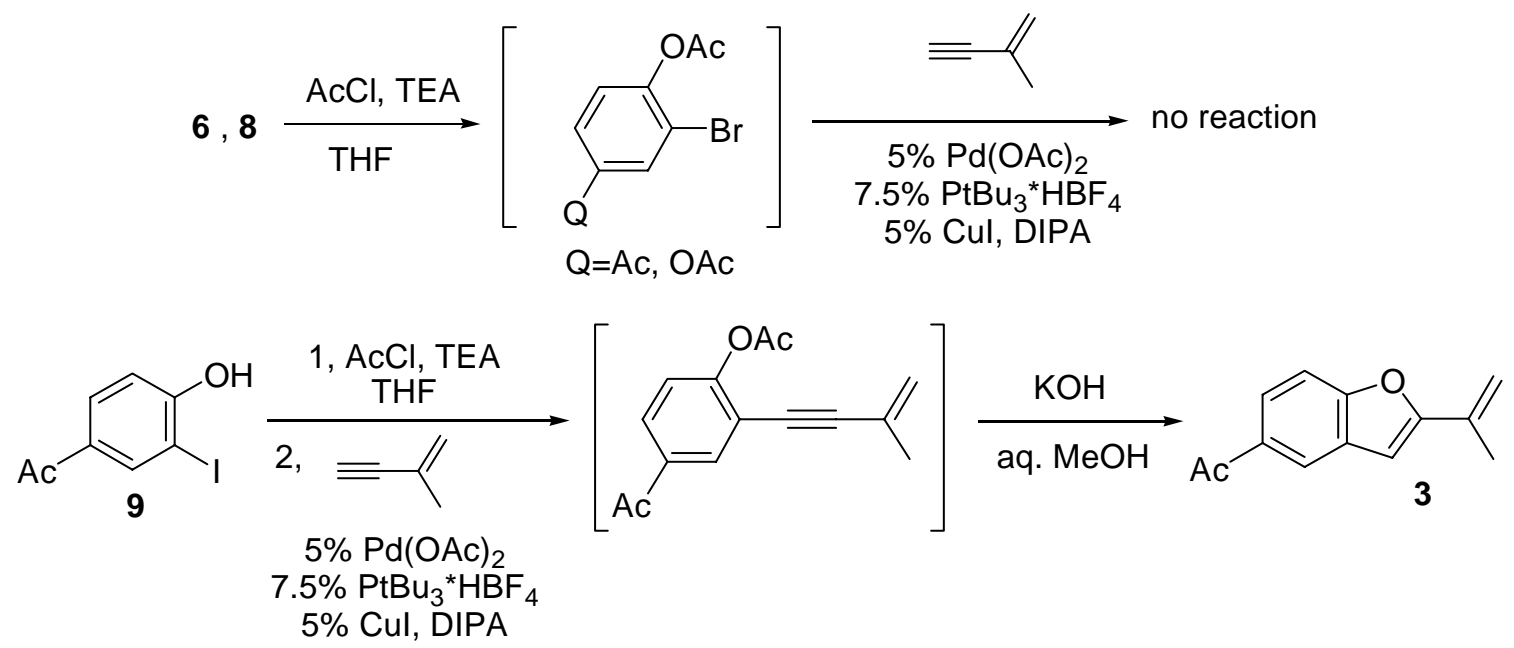

\section{Figure 4}

Starting from 4-hydroxy-3-iodoacetophenone (9), following acetylation, we were able to achieve a near complete conversion in the Sonogashira coupling with 2-methyl-1-buten-3-yne. Leaving the coupling to run at $40{ }^{\circ} \mathrm{C}$ (oil bath temperature) we observed a ca. 95\% conversion after 60 hours. Removal of the protecting group and spontaneous ring closure afforded the expected product, dehydrotremetone (3) in 50\% yield following chromatographic purification. ${ }^{21}$ It is interesting to note that, based on the TLC examination of the reaction mixture, the removal of the acetyl group and the spontaneous ring closure to benzofuran is initiated already at the Sonogashira coupling stage, and potassium hydroxide and aqueous methanol are required only to drive this process to completion.

\section{Conclusions}

In summary, we have demonstrated that our recently published procedure that allows the one-pot preparation of substituted benzofurans from hydroxylated halobenzenes, can be extended to the efficient synthesis of benzofuran derivatives bearing biologically relevant substituents such as 
hydroxyl, acetyl or 2-propenyl groups. In the course of this research we elaborated a convenient preparation for the natural product dehydrotremetone.

\section{Experimental Section}

General Procedures. The ${ }^{1} \mathrm{H}$ and ${ }^{13} \mathrm{C}$ NMR spectra were recorded on a Brucker DRX-250 spectrometer in $\mathrm{CDCl}_{3}$ and $\mathrm{CD}_{3} \mathrm{SOCD}_{3}$. For ${ }^{1} \mathrm{H}$ NMR spectra the residual peak of $\mathrm{CHCl}_{3}$ (7.26 ppm) and the central peak of $\mathrm{CH}_{3} \mathrm{SOCH}_{3}(2.50 \mathrm{ppm})$ were used as the internal reference, while for ${ }^{13} \mathrm{C}$ NMR spectra the central peaks of $\mathrm{CDCl}_{3}(77.0 \mathrm{ppm})$ and $\mathrm{CD}_{3} \mathrm{SOCD}_{3}(39.43 \mathrm{ppm})$ were used as the reference. The IR spectra were obtained on a Bruker IFS-55 FTIR spectrometer. Combination gas chromatography and low resolution mass spectrometry was obtained on a Hewlett-Packard 5790A Gas Chromatograph (30 m x 0.25 mm column with $0.25 \mu \mathrm{m} \mathrm{RH}-5 \mathrm{MS}+$ coating, He carrier gas) and VG 12-250 Mass Spectrometer (Ion source: $\mathrm{EI}+, 70 \mathrm{eV}, 250^{\circ} \mathrm{C}$; interface: $250^{\circ} \mathrm{C}$ ). Silica gel was used for flash column chromatography.

2-Phenyl-5-hydroxy-benzofuran (7). ${ }^{22}$ A dry Schlenk flask was charged with 6 (378 mg, 2 mmol), triethylamine (404 mg, $556 \mu \mathrm{l}, 4 \mathrm{mmol}$ ) and abs.THF (2.4 mL). Acetyl chloride (314 mg, $284 \mu \mathrm{l}, 4 \mathrm{mmol}$ ) was added dropwise to the solution at $25^{\circ} \mathrm{C}$ followed in 5 minutes by diisopropylamine (2.4 mL), $\mathrm{Pd}(\mathrm{OAc})_{2}$ (22.4 mg, $0.1 \mathrm{mmol}$ ), $\mathrm{P}^{\mathrm{t}} \mathrm{Bu}_{3}{ }^{*} \mathrm{HBF}_{4}$ (43.4 mg, $0.15 \mathrm{mmol}$ ), $\mathrm{CuI}$ (19 mg, $0.1 \mathrm{mmol}$ ) and phenylacetylene (408 mg, $440 \mu \mathrm{l}, 4 \mathrm{mmol}$ ). The reaction was purged with argon and it was stirred at $60^{\circ} \mathrm{C}$. After full conversion (approximately 2 hours) $\mathrm{MeOH}$ $(8 \mathrm{~mL})$ and water $(1.6 \mathrm{~mL})$ containing $\mathrm{KOH}(1.12 \mathrm{~g}, 20 \mathrm{mmol})$ was added to the reaction mixture and stirring was continued at $75^{\circ} \mathrm{C}$ for 2 hours. The mixture was cooled to $25^{\circ} \mathrm{C}$ and neutralized with $10 \% \mathrm{HCl}$. The resulting suspension was extracted with DCM, and the organic phase was dried over $\mathrm{MgSO}_{4}$. After removal of the solvent, the crude product was purified by column chromatography to afford 7 (220 mg, $1.05 \mathrm{mmol})$ as a pale brown solid. Yield: $52 \%$. ${ }^{1} \mathrm{H}$ NMR $\left(\mathrm{CD}_{3} \mathrm{SOCD}_{3} ; 250 \mathrm{MHz}\right): \delta 9.23(\mathrm{~s}, 1 \mathrm{H}), 7.87$ (d, 2H, J= $\left.7.5 \mathrm{~Hz}\right), 7.48(\mathrm{t}, 2 \mathrm{H}, J=7.5 \mathrm{~Hz})$, 7.39-7.42 (m, 2H), 7.28 (s, 1H), 6.95 (d, 1H, J=2.3 Hz), 6.75 (dd, $1 \mathrm{H}, J=8.8 \mathrm{~Hz}, 2.3 \mathrm{~Hz}$ ); ${ }^{13} \mathrm{C}$ NMR (CD $\left.\mathrm{SOCD}_{3}, 62.5 \mathrm{MHz}\right): \delta 155.9,153.9,148.8,130.3,129.9,129.3,129.0,124.8,113.7$, 111.7, 105.7, 102.3; MS (EI, 70eV) m/z (\% relative intensity, ion): 210(100, $\left[\mathrm{M}^{+}\right]$), 209(82), 181(13), 152(16), 105(9), 76(17); IR(KBr) $v_{\max }$ : 3292, 1596, 1468, 1455, 1405, 1201, 916, 806, $758 \mathrm{~cm}^{-1}$.

2-Phenyl-5-acetyl-benzofuran (10). ${ }^{23}$ A dry Schlenk flask was charged with 8 (430 mg, $2 \mathrm{mmol}$ ), triethylamine (202 mg, $280 \mu \mathrm{l}, 2 \mathrm{mmol})$ and abs.THF (2.4 mL). Acetyl chloride (157 $\mathrm{mg}, 143 \mu \mathrm{l}, 2 \mathrm{mmol}$ ) was added dropwise to the solution at $25^{\circ} \mathrm{C}$ followed in 5 minutes by diisopropylamine (2.4 mL), $\mathrm{Pd}(\mathrm{OAc})_{2}$ (22.4 mg, $0.1 \mathrm{mmol}$ ), $\mathrm{P}^{\mathrm{t}} \mathrm{Bu}_{3}{ }^{*} \mathrm{HBF}_{4}$ (43.4 mg, $0.15 \mathrm{mmol}$ ), $\mathrm{CuI}$ (19 mg, $0.1 \mathrm{mmol}$ ) and phenylacetylene (408 mg, $440 \mu \mathrm{l}, 4 \mathrm{mmol}$ ). The reaction was purged with argon and it was stirred at $70^{\circ} \mathrm{C}$. After full conversion (approximately 2 hours) $\mathrm{MeOH}$ $(8 \mathrm{~mL})$ and water $(1.6 \mathrm{~mL})$ containing $\mathrm{KOH}(1.12 \mathrm{~g}, 20 \mathrm{mmol})$ was added to the reaction mixture 
and stirring was continued at $75^{\circ} \mathrm{C}$ for 2 hours. The mixture was cooled to $25^{\circ} \mathrm{C}$ and neutralized with $10 \% \mathrm{HCl}$. The resulting suspension was extracted with DCM, and the organic phase was dried over $\mathrm{MgSO}_{4}$. After removal of the solvent the crude product was purified by column chromatography to afford 10 (350 mg, $1.48 \mathrm{mmol}$ ) as a yellow solid. Yield: 74 \%. Starting from 9 (524 mg, $2 \mathrm{mmol}$ ) the same procedure gave 10 in $57 \%$ yield (270 mg, $1.14 \mathrm{mmol}$ ). ${ }^{1} \mathrm{H}$ NMR $\left(\mathrm{CDCl}_{3}\right.$; 250MHz): $\delta 8.08$ (s, 1H), 7.82 (d, 1H, $\left.J=8.8 \mathrm{~Hz}\right), 7.74$ (d, 2H, J= 7.6 Hz). 7.41 (d, 1H,

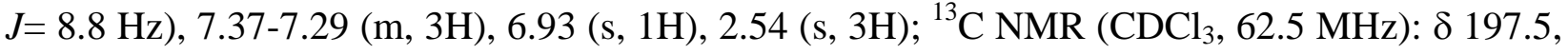
157.4, 157.3, 132.8, 129.7, 129.2, 129.0, 128.8, 125.0, 124.9, 122.0, 111.0, 101.5, 26.7; MS (EI, $70 \mathrm{eV}) \mathrm{m} / \mathrm{z}$ (\% relative intensity, ion): 236(100, $\left.\left[\mathrm{M}^{+}\right]\right), 221(95), 220(90), 193(50), 192(28)$, 165(12), 82(22); IR(KBr) $v_{\max }: 2926,1673,1607,1566,1356,1272,907,807,751 \mathrm{~cm}^{-1}$.

2-isoPropenyl-5-acetyl-benzofuran (dehydrotremetone) (3). ${ }^{7}$ A dry Schlenk flask was charged with 9 (262 mg, $1 \mathrm{mmol}$ ), triethylamine (101 mg, $140 \mu \mathrm{l}, 1 \mathrm{mmol})$ and abs.THF (1.2 mL). Acetyl chloride (79 mg, $72 \mu \mathrm{l}, 1 \mathrm{mmol}$ ) was added dropwise to the solution at $25^{\circ} \mathrm{C}$ followed in 5 minutes by diisopropylamine (1.2 mL), $\mathrm{Pd}(\mathrm{OAc})_{2}$ (11.2 mg, $\left.0.05 \mathrm{mmol}\right), \mathrm{P}^{\mathrm{t}} \mathrm{Bu}_{3} * \mathrm{HBF}_{4}(21.7 \mathrm{mg}$, $0.075 \mathrm{mmol}$ ), CuI (10 mg, $0.05 \mathrm{mmol}$ ) and 2-methyl-1-buten-3-yne (264 mg, $380 \mu \mathrm{l}, 4 \mathrm{mmol}$ ). The reaction was purged with argon and it was stirred at $40^{\circ} \mathrm{C}$. After 60 hours $\mathrm{MeOH}(4 \mathrm{~mL})$ and water $(0.8 \mathrm{~mL})$ containing $\mathrm{KOH}(560 \mathrm{mg}, 10 \mathrm{mmol})$ was added to the reaction mixture and stirring was continued at $75^{\circ} \mathrm{C}$ for 2 hours. The mixture was cooled to $25^{\circ} \mathrm{C}$ and neutralized with $10 \% \mathrm{HCl}$. The resulting suspension was extracted with DCM, and the organic phase was dried over $\mathrm{MgSO}_{4}$. After removal of the solvent the crude product was purified by column chromatography to afford $3(100 \mathrm{mg}, 0.50 \mathrm{mmol})$ as a white solid. Yield: $50 \% .{ }^{1} \mathrm{H} \mathrm{NMR}\left(\mathrm{CDCl}_{3}\right.$; 250MHz): $\delta 8.16$ (d, 1H, $J=1.8 \mathrm{~Hz}$ ), 7.92 (dd, 1H, $J=8.5,1.8 \mathrm{~Hz}$ ), 7.46 (d, 1H, $J=8.5 \mathrm{~Hz}$ ), 6.68 (s, 1H), 5.82 (s, 1H), 5.23 (t, 1H, J=1.3 Hz), 2.64 (s, 3H), 2.13 (s, 3H); ${ }^{13} \mathrm{C} \mathrm{NMR} \mathrm{(CDCl}, 62.5$ MHz): $\delta$ 197.6, 158.4, 157.3, 132.6, 132.4, 129.1, 125.3, 122.1, 114.2, 110.9, 103.1, 26.7, 19.2; MS (EI, 70eV) m/z (\% relative intensity, ion): 200(60 $\left.\left[\mathrm{M}^{+}\right]\right), 199(29), 185(100), 184(48)$, 157(32), 128(13), 92(18), 77(18), 63(11); IR(KBr) $v_{\max }$ : 2925, 1669, 1635, 1584, 1557, 1361, 1299, 1268, 1156, 914, $811 \mathrm{~cm}^{-1}$.

\section{Acknowledgements}

The authors acknowledge the financial support of the Hungarian Ministry of Education (FKFP 0125/2001) and the Alexander von Humboldt Foundation.

\section{References}

1. Keay, B. A. In Comprehensive Heterocyclic Chemistry II,; Katritzky, A. R.; Rees, C. W.; Scriven, E. F. V., Eds; Pergamon Press; Oxford, 1996, Vol. 2395.

2. Schneiders, G. E.; Stevenson, R. J. Org. Chem. 1979, 44, 4710. 
3. Yang, Z. et al. Tetrahedron Lett. 1991, 32, 2061.

4. Murae, T.; Tanahashi, Y.; Takahashi, T. Tetrahedron 1968, 24, 2177.

5. Kamthong, B.; Robertson, A. J. Chem. Soc. 1939, 925.

6. Emerson, O. H.; Bickoff, E. M. J. Am. Chem. Soc. 1958, 80, 4381.

7. DeGraw, J.; Bonner, W. A. J. Org. Chem. 1962, 27, 3917.

8. Stevenson, P. C.; Veitch, N. C. Phytochemistry 1998, 48, 947.

9. Soós, T.; Timári, G.; Hajós, G. Tetrahedron Lett. 1999, 40, 8607.

10. Friedrichsen, W. In Comprehensive Heterocyclic Chemistry II.; Katritzky, A. R.; Rees, C. W.; Scriven, E. F. V., Eds.; Pergamon Press: Oxford, 1996; Vol. 2, p 351.

11. Arcadi, A.; Cacchi, S.; Di Giuseppe, S.; Fabrizi, G.; Marinelli, F. Synlett 2002, 453.

12. Hiroya, K.; Suzuki, N.; Yasuhara, A.; Egawa, Y.; Kasano, A.; Sakamoto, T. J. Chem. Soc. Perkin Trans. 1. 2000, 4339.

13. Kundu, N. G.; Pal, M.; Mahanty, J. S.; De, M. J. Chem. Soc. Perkin Trans. 1. 1997, 2815.

14. Arcadi, A.; Cacchi, S.; Del Rosario, M.; Fabrizi, G.; Marinelli, F. J. Org. Chem. 1996, 61, 9280 .

15. Schreiber, F. G.; Stevenson, R J. Chem. Soc., Perkin Trans. 1. 1977, 90.

16. Novák, Z.; Timári, G.; Kotschy, A. Tetrahedron 2003, 59, 7509.

17. Hundertmark, T.; Littke, A. F.; Buchwald, S. L.; Fu, G. C. Org. Lett. 2000, 2, 1729.

18. Netherton, M. R.; Fu, G. C. Org. Lett. 2001, 3, 4295.

19. Leclerc, G.; Bizec, J. C.; Bieth, N. J.Schwartz J. Med. Chem. 1980, 23, 738.

20. Tillu, V. H.; Shinde, P. D.; Bedekar, A. V.; Wakharkar, R. D. Synth. Commun. 2003, 33, 1399.

21. Since the submission of the manuscript we have found that 9 reacts readily with 2-methyl-1buten-3-yne without protection of the hydroxyl group, and dehydrotremetone (3) is isolated in $85 \%$ yield after 8 hours.

22. Domschke, G. J. Prakt. Chem. 1966, 32, 144.

23. Ota, T.; Hasegawa, S.; Inoue, S.; Sato, K. J. Chem. Soc., Perkin Trans. 1 1988, 3029. 